\title{
Incidence of cardiovascular risk factors by education level 2000-2005: the Australian diabetes, obesity and lifestyle (AusDiab) Cohort Study
}

\author{
Alison Beauchamp \\ School of Nursing, Monash University, Victoria, Australia \\ Heart Research Centre, Melbourne, Australia \\ alison.beauchamp@monash.edu
}

\section{Rory Wolfe}

Department of Epidemiology and Preventive Medicine, Monash University, Melbourne, Australia

\section{Dianna J Magliano}

Department of Epidemiology and Preventive Medicine, Monash University, Melbourne, Australia International Diabetes Institute, Melbourne, Australia

\section{Gavin Turrell}

School of Public Health, Queensland University of Technology, Brisbane, Australia

\section{Andrew Tonkin}

Department of Epidemiology and Preventive Medicine, Monash University, Melbourne, Australia Jonathan Shaw

Department of Epidemiology and Preventive Medicine, Monash University, Melbourne, Australia, International Diabetes Institute, Melbourne, Australia

\section{Anna Peeters}

Department of Epidemiology and Preventive Medicine, Monash University, Melbourne, Australia

(Received January 2011 Revised June 2011)

\section{Abstract}

Lower socio-economic position (SEP) is associated with a higher prevalence of major risk factors for cardiovascular disease (CVD). However, few longitudinal studies have examined the association between SEP and CVD risk factors over time. We aimed to determine whether educational attainment is associated with the onset of CVD risk factors over 5 years in an Australian adult cohort study. Participants in the Australian Diabetes, Obesity and Lifestyle study (AusDiab) study aged 25 years and over, who attended both baseline and 5-year follow-up examinations $(n=5,568)$ were categorised according to educational attainment. Cardiovascular risk factor data at both time points were ascertained through questionnaire and physical measurement. Women with lower education had a greater risk of progressing from normal weight to overweight or obesity than those with higher education (adjusted $O R$ 1.54, 95\% Cl 1.04-2.27). Both men and women with lower education were more likely to develop diabetes (adjusted OR from higher education 1.71, 95\% Cl 1.10-2.66 and 3.09, 95\% Cl 1.28-7.42, respectively). A lower level of education was associated with a greater increase in the number of risk factors accumulated over time in women. In this Australian population-based study, lower educational attainment was associated with an increased risk of developing overweight/ obesity and diabetes over a 5-year period in women. Men with lower education were also more likely to develop incident diabetes than those with higher education. These findings suggest that social inequalities in CVD will persist into the future.

Keywords: Socio-economic position, risk factor incidence, cardiovascular disease, diabetes, obesity 


\section{Background}

Cardiovascular disease is the leading cause of death globally, with the burden of disease greater among lower socio-economic groups (Kaplan and Keil 1993; Australian Institute of Health and Welfare (AlHW) 2006; Mackenbach et al 2008). Such inequalities do not just affect the most disadvantaged groups in a society. There is clear evidence for a social gradient in CVD that runs across the entire socio-economic spectrum so that overall, the lower an individual's socio-economic position, the worse their cardiovascular health (Lynch et al 2006; Marmot et al 2008; Marmot 2010). For example, the Whitehall Study of British civil servants was instrumental in demonstrating that inequalities in CVD exist across all occupational classes (Marmot 1992). While the mechanisms and pathways underlying this social gradient in CVD are not fully understood, major risk factors for atherothrombotic disease are thought to play a significant role. Tobacco smoking, abnormal lipids, high blood pressure, diabetes and abdominal obesity in combination, account for up to $90 \%$ of the population attributable risk (PAR) of acute myocardial infarction (Yusuf et al 2004). In addition, many longitudinal studies have reported that social gradients in the prevalence of these and other risk factors account for a significant proportion of the social gradient in CVD (Lynch et al 1996; Beauchamp et al 2010). People from lower socio-economic groups also tend to have a higher number of cardiovascular risk factors, leading to an increased overall risk of CVD among the more disadvantaged (AlHW 2005).

Despite this evidence, our understanding of how social gradients in CVD risk develop in individuals over time remains limited. Prospective studies describing the incidence of cardiovascular risk factors according to socio-economic position (SEP) are few, and findings are inconsistent. While several studies have found that the incidence of hypertension is higher among lower socio-economic groups, [Conen et al 2009; Diez Roux et al 2002; Mathews et al 2002), others have shown that these associations vary according to age, race and gender (Dyer et al 1999; Ford and Cooper 1991; Vargas et al 2000). Findings are equally inconsistent for incident obesity (Ball and Crawford 2005; Martikainen and Marmot 1999; Mujahid et al 2005) and diabetes (Kumari et al 2004; Maty et al 2005; Maty et al 2010; Robbins et al 2005). In addition, while it is known that risk factors in combination are more closely associated with CVD risk than single factors in isolation (NVDPA 2009), and that lower SEP groups tend to have a greater number of cardiovascular risk factors (AlHW 2005), few longitudinal studies have examined whether SEP is associated with the accumulation of cardiovascular risk factors over time (Dupre 2008). Further evidence for the association between SEP and the incidence of both individual and cumulative risk factors will make an important contribution to our knowledge of which factors to target in order to reduce future inequalities in CVD.

Using data from an Australian adult cohort study, we aimed to determine whether educational attainment (as an indicator of SEP) is both a predictor of incident cardiovascular risk factors, and is associated with the development of a greater number of risk factors over time.

\section{Methods}

The Australian Diabetes, Obesity and Lifestyle study (AusDiab) is a population-based, stratified cluster survey of 11,247 adults aged 25 years or older in $1999-2000$. Methods and response rates have been described previously (Dunstan et al 2002). A five-year follow-up was conducted in 2004-2005. From the original cohort there were 10,788 participants eligible for follow-up and of these, 6400 returned for physical examination and interviewer-administered questionnaire. For this analysis we excluded participants missing baseline data on education $(n=47)$, diabetes or CVD $(n=72)$, and baseline or follow-up data on smoking, systolic blood pressure, cholesterol, body mass index (BMI), and medication use ( $n=314)$, leaving 5,967 participants who had attended both baseline and follow-up examinations. We excluded a further 399 participants with self-reported history of CVD at baseline, leaving a total of 5,568 participants. Ethics approval was obtained from the International Diabetes Institute and Monash University, Melbourne. All participants consented to participate in the study.

Education level was ascertained by asking the question "Which of these describes the highest qualification you have received?" Education was categorised as secondary only (comprising those with a secondary school qualification), diploma (comprising nursing or teaching qualification, trade certificate or undergraduate diploma), and degree 
(comprising bachelor degree, post-graduate diploma or masters degree/doctorate). These categories are considered to represent hierarchical stages of education, each of which has important socio-economic implications (Dutton 2005).

Baseline and follow-up assessments followed a similar protocol. Data were collected by interviewer-administered questionnaires on age, sex and current use of anti-hypertensive and lipidlowering medications. Self-reported CVD was ascertained by asking if participants had been told by a doctor or nurse that they had angina, coronary heart disease, or stroke. Smoking status was defined as 1) current daily smoker and 2) ex-smoker (now smoking less than daily for at least the last 3 months, but used to smoke daily) and non-smoker (never smoked tobacco daily) combined.

Blood pressure was measured using a Dinamap or a standard mercury sphygmomanometer (Briganti et al 2003). Height and weight were measured using standard methods, (Briganti et al 2003; Dalton et al 2003) and BMI was calculated as weight $(\mathrm{kg}) /$ height $(\mathrm{m})^{2}$. (Dalton et al. 2003) Fasting serum total cholesterol was measured with an Olympus AU600 analyser (Olympus Optical, Tokyo, Japan) at a central laboratory (Magliano et al 2007).

Classification of diabetes status has been described elsewhere (Magliano et al 2007). Briefly, participants were classified as having 'known diabetes mellitus' if they reported having physiciandiagnosed diabetes mellitus and were either taking hypoglycaemic medication or had fasting plasma glucose $(F P G) \geq 7.0 \mathrm{mmol} / \mathrm{L}$ or a 2 -hour plasma glucose $(P G) \geq 11.1 \mathrm{mmol} / \mathrm{L}$. Participants not reporting diabetes mellitus but with FPG $\geq 7.0$ $\mathrm{mmol} / \mathrm{L}$ or 2 -hour PG $\geq 11.1 \mathrm{mmol} / \mathrm{L}$ were classified as having 'newly diagnosed diabetes mellitus'.

\section{Statistical analysis}

Analyses were conducted using sample weights to account for the sampling design of the study (Dunstan et al 2002). For continuous risk factor variables, the significance of a trend across educational categories was assessed using linear regression. For dichotomous variables, the significance of a trend across educational categories was assessed using logistic regression. Two-sided $p$ values are presented, with $p$-values $<0.05$ regarded as significant.
For each individual risk factor at baseline, we created "low risk" groups according to baseline measurement or use of prescription medication for that risk factor. The cut-point for being considered "low risk" for hypertension was a baseline systolic blood pressure reading of $<140 \mathrm{mmHg}$ or a baseline diastolic blood pressure reading of $<90 \mathrm{mmHg}$, and not on anti-hypertensive medication. For cholesterol, the cut-point for being "low risk" was $<5.5 \mathrm{mmol} / \mathrm{l}$ and not on cholesterol-lowering medication at baseline, and for BMI, the cut-point was $<25 \mathrm{~kg} / \mathrm{m}^{2}$.

We used logistic regression to analyse the incidence of risk in those participants designated "low risk" according to these cut-points. The odds ratios represent the odds of progressing from being "low risk" at baseline to "high risk" at follow-up for that risk factor within each education category, relative to the highest educated group. Three models are presented; model 1 (unadjusted), model 2 (adjusted for age and ethnicity), and model 3 (adjusted for age, ethnicity and baseline measure of that risk factor). Linear regression was used to describe the association between education and the number of risk factors at follow up, adjusting for the number of risk factors at baseline. This analysis reports the increase in risk factors over time according to educational attainment. Tests of interaction between education and sex were significant for diabetes and therefore results of sexstratified analyses are presented.

\section{Results}

\section{Non-attendees}

Baseline characteristics were compared between participants who attended follow-up and those who did not (data not shown). Compared to those who did attend, non-attendees were on average 2 years older. Mean levels of systolic blood pressure, cholesterol, and BMI were similar between the two groups. The prevalence of smoking in male non-attendees according to educational category was $28 \%, 28 \%$ and $15 \%$ for secondary, diploma and degree-educated groups, respectively, and for female non-attendees was $24 \%, 21 \%$ and $14 \%$, respectively. Diabetes prevalence in male non-attendees was $10 \%, 9 \%$ and $5 \%$ for secondary, diploma and degree-educated groups, respectively, and $9 \%, 6 \%$ and $4 \%$, respectively for female non-attendees. For men, the odds of not attending (when eligible) were 1.60 
(95\% Cl 1.33-1.93) times greater for those with secondary compared to tertiary education and 1.30 $(95 \% \mathrm{Cl} 1.12-1.51)$ times greater for those with diploma compared to tertiary education. For women, the odds of not attending (when eligible) were $1.65(95 \% \mathrm{Cl} 1.40-1.95)$ and $1.32(95 \% \mathrm{Cl} 1.12-$ $1.51)$, respectively.

The baseline characteristics of study participants are shown in Table 1. Compared to the lower educated groups, participants with degree level education were younger. Inverse gradients were observed for most risk factors, reflecting a more adverse risk factor profile and a greater likelihood of being at "high risk" for those with lower education compared to those with higher education. The numbers of risk factors at baseline (out of a total number of 5) also differed according to education for both men and women, with lower educated participants having the greater number.

Table 2 presents mean risk factor levels for those participants defined as "low risk" for each risk factor according to the cut-points described earlier. For men, educational gradients were seen for fasting blood glucose only. Among women, inverse educational gradients were seen for all risk factors with the exception of diastolic blood pressure.

\section{Incidence of risk factors}

The likelihood of progression to "high risk" for each risk factor according to education level is shown in Table 3 . In age and ethnicity-adjusted analyses, women with secondary education and those with diploma level education were more likely to progress to increased risk for BMI (OR compared to degree level education $1.54(95 \% \mathrm{Cl}$ 1.04-2.27) and $1.70(95 \% \mathrm{Cl} 1.24-2.34)$ respectively). This association became non significant after adjustment for baseline BMI. Women with secondary and diploma level education were also more likely to develop incident diabetes than were those with higher education (adjusted OR from degree level education 3.09 ( $95 \% \mathrm{Cl} 1.28-7.42)$, and from diploma level education $2.65(95 \% \mathrm{Cl} 1.11$, 6.30). Among men, this association was seen only for those with secondary education (adjusted OR from degree level education 1.71 (95\% Cl 1.102.66). After adjusting for baseline FBG level, the associations between education and diabetes remained significant for both men and women. 


\section{Table 1. Baseline risk factor measures, prevalence and number of risk factors in 5,568 AusDiab men and women participants, by educational attainment}

Men

Highest level of education

\begin{tabular}{|c|c|c|c|c|c|c|c|c|c|}
\hline & & $\begin{array}{c}\text { Secondary } \\
\quad(n=668)\end{array}$ & $\begin{array}{l}\text { Diploma } \\
(n=1,234)\end{array}$ & $\begin{array}{l}\text { Degree } \\
(n=582)\end{array}$ & p-value ${ }^{1}$ & $\begin{array}{c}\text { Secondary } \\
(n=1,374)\end{array}$ & $\begin{array}{l}\text { Diploma } \\
(n=1,177)\end{array}$ & $\begin{array}{l}\text { Degree } \\
(n=533)\end{array}$ & p-value ${ }^{1}$ \\
\hline Age & mean (SD) & $52.6(12.8)$ & $50.9(12.3)$ & $47.9(11.2)$ & $<0.001$ & $53.1(12.4)$ & $50.0(11.8)$ & $45.1(10.1)$ & $<0.001$ \\
\hline Systolic BP & mean (SD) & $133.9(16.8)$ & $131.4(15.9)$ & $130.1(15.6)$ & 0.001 & $128.1(19.0)$ & $124.3(17.1)$ & $119.1(14.5)$ & $<0.001$ \\
\hline Diastolic BP & mean (SD) & $75.4(10.6)$ & $74.5 \quad(10.6)$ & $74.8(10.6)$ & 0.33 & $67.2(11.1)$ & $65.9(11.0)$ & $65.5(10.0)$ & 0.001 \\
\hline Hypertension $^{2}$ at baseline & $\mathrm{n}(\%)$ & $256(38 \%)$ & $392(32 \%)$ & $147(25 \%)$ & $<0.001$ & $451(33 \%)$ & $284(24 \%)$ & $64(12 \%)$ & $<0.001$ \\
\hline Total cholesterol & mean (SD) & $5.71(1.01)$ & $5.75(1.03)$ & $5.57(0.97)$ & 0.004 & $5.75(1.03)$ & $5.64(1.01)$ & $5.27(1.01)$ & $<0.001$ \\
\hline Hypercholesteraemia $^{2}$ at baseline & $\mathrm{n}(\%)$ & $425(64 \%)$ & $775(63 \%)$ & $328(56 \%)$ & 0.010 & $879(64 \%)$ & $688(58 \%)$ & $219(41 \%)$ & $<0.001$ \\
\hline Body mass index & mean (SD) & $27.5(4.1)$ & $27.1(3.9)$ & $26.6(3.9)$ & $<0.001$ & $27.0(5.3)$ & $26.6(5.6)$ & $25.4(5.0)$ & $<0.001$ \\
\hline Overweight/obese $^{2}$ at baseline & $\mathrm{n}(\%)$ & $480(72 \%)$ & $866(70 \%)$ & $377(65 \%)$ & 0.002 & $832(61 \%)$ & $619(53 \%)$ & $240(45 \%)$ & $<0.001$ \\
\hline Fasting blood glucose & mean (SD) & $5.79(1.19)$ & $5.70(0.86)$ & $5.63(1.04)$ & 0.007 & $5.45(1.00)$ & $5.36(0.92)$ & $5.20(0.83)$ & $<0.001$ \\
\hline Diabetes $^{2}$ at baseline & $\mathrm{n}(\%)$ & $62(9 \%)$ & $86(7 \%)$ & $28(5 \%)$ & 0.002 & $94(7 \%)$ & $55(5 \%)$ & $12(2 \%)$ & 0.002 \\
\hline Smoking $^{2}$ at baseline & $\mathrm{n}(\%)$ & $126(19 \%)$ & $162(13 \%)$ & $44(8 \%)$ & 0.000 & $157(11 \%)$ & $116(10 \%)$ & $30(6 \%)$ & 0.002 \\
\hline Proportion with no risk factors ${ }^{2}$ & n (\%) & $47(7 \%)$ & $125(10 \%)$ & $94(16 \%)$ & $<0.001$ & $168(12 \%)$ & $243(21 \%)$ & $169(32 \%)$ & $<0.001$ \\
\hline Proportion with one risk factor ${ }^{2}$ & $\mathrm{n}(\%)$ & $165(25 \%)$ & $325(26 \%)$ & $172(30 \%)$ & 0.06 & $416(30 \%)$ & $369(31 \%)$ & 209 (39\%) & $<0.001$ \\
\hline Proportion with two risk factors ${ }^{2}$ & n (\%) & $235(35 \%)$ & $455(37 \%)$ & $210(36 \%)$ & 0.75 & $431(31 \%)$ & $333(28 \%)$ & $111(21 \%)$ & $<0.001$ \\
\hline Proportion with three risk factors ${ }^{2}$ & n (\%) & $166(25 \%)$ & $255(21 \%)$ & $89(15 \%)$ & $<0.001$ & $291(21 \%)$ & $189(16 \%)$ & $40(8 \%)$ & $<0.001$ \\
\hline Proportion with four risk factors ${ }^{2}$ & $\mathrm{n}(\%)$ & $51(8 \%)$ & $71(6 \%)$ & $16(3 \%)$ & $<0.001$ & $59(4 \%)$ & $43(4 \%)$ & $4(1 \%)$ & 0.004 \\
\hline Proportion with five risk factors ${ }^{2}$ & n (\%) & $4(0.6 \%)$ & $3(0.2 \%)$ & $1(0.2 \%)$ & 0.28 & $9(1 \%)$ & 0 & 0 & \\
\hline
\end{tabular}

Notes: ${ }^{1} P$-value for continuous variables = trend across education categories using linear regression; for proportions = trend across education categories using logistic regression. Abbreviations $B P=$ blood pressure; ${ }^{2}$ Risk factors defined as follows: hypertension (systolic blood pressure $\geq 140 \mathrm{mmHg}$ or diastolic blood pressure $\geq 90 \mathrm{mmHg}$ or on

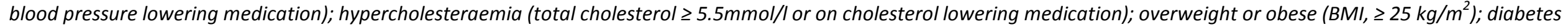
(known or newly diagnosed); smoking (current smoker). 
Table 2. Mean risk factor measurements in those AusDiab men and women considered “low risk"1 at baseline, by educational attainment

Men

Highest level of education

\begin{tabular}{|c|c|c|c|c|c|c|c|c|c|}
\hline & & & Me & & & & Wom & & \\
\hline & & & lighest level c & education & & & Highest level o & ducation & \\
\hline & & Secondary & Diploma & Degree & p-value ${ }^{2}$ & Secondary & Diploma & Degree & p-value ${ }^{2}$ \\
\hline Systolic BP & mean (SD) if "not at risk" & $124.4(9.3)$ & $123.4(9.1)$ & $123.8(9.8)$ & 0.38 & $118.7(11.0)$ & $117.6(11.1)$ & $115.7(10.3)$ & $<0.001$ \\
\hline Diastolic BP & mean (SD) if "not at risk" & $73.1(9.1)$ & $72.1(8.8)$ & $72.4(8.7)$ & 0.20 & 65.7 (9.9) & $64.6(10.2)$ & $65.0(9.7)$ & 0.06 \\
\hline Total cholesterol & mean (SD) if "not at risk" & $4.75(0.52)$ & $4.80(0.47)$ & $4.77(0.50)$ & 0.72 & $4.78(0.52)$ & $4.75(0.51)$ & $4.63(0.62)$ & 0.010 \\
\hline Body mass index & mean (SD) if "not at risk" & $23.0(1.6)$ & $23.0(1.6)$ & $22.8(1.5)$ & 0.30 & $22.4(1.7)$ & $22.3(1.8)$ & $21.9(1.8)$ & 0.002 \\
\hline $\begin{array}{l}\text { Fasting blood } \\
\text { glucose }\end{array}$ & mean (SD) if "not at risk" & $5.38(0.32)$ & $5.37(0.35)$ & $5.33(0.31)$ & 0.032 & $5.19(0.36)$ & $5.17(0.39)$ & $5.07(0.36)$ & $<0.001$ \\
\hline
\end{tabular}

Notes: " "Low risk" defined for each risk factor as follows: : For hypertension, systolic blood pressure $<140 \mathrm{mmHg}$ or diastolic blood pressure < $90 \mathrm{mmHg} \&$ not on blood pressure lowering medication; for cholesterol < 5.5mmol/I \& not on treatment; BMI, $25,<25 \mathrm{~kg} / \mathrm{m}^{2}$ or less; for diabetes, no known or newly diagnosed diabetes; for fasting blood glucose $\leq 6.0 \mathrm{mmol} / \mathrm{L}$; for smoking former or non-smoker ${ }^{2} P$-value for continuous variables = trend across education categories using linear regression; $A b b r e v i a t i o n s ; ~ B P=b l o o d$ pressure; $S D=$ standard deviation

\section{Women}

\section{Highest level of education}


Table 3. Risk of incident risk factors at 5-year follow-up in men and women AusDiab participants according to educational attainment

Model $\mathbf{1}^{1}$

\begin{tabular}{|c|c|c|c|c|c|c|c|c|c|c|c|c|c|c|}
\hline & \multicolumn{5}{|c|}{ Model $1^{1}$} & \multirow{2}{*}{\multicolumn{4}{|c|}{$\begin{array}{c}\text { Model } 2^{2} \\
\text { Men }\end{array}$}} & \multicolumn{5}{|c|}{ Model $3^{3}$} \\
\hline & & & & & & & & & & \\
\hline & & Secon & dary & Diplo & ma & \multicolumn{2}{|c|}{ Secondary } & \multicolumn{2}{|c|}{ Diploma } & \multicolumn{2}{|c|}{ Secondary } & \multicolumn{2}{|c|}{ Diploma } & \multirow{2}{*}{$\begin{array}{l}\text { Degree } \\
\text { (reference } \\
\text { category for } \\
\text { all models) }\end{array}$} \\
\hline & $n$ & OR & $(95 \% \mathrm{Cl})$ & $O R$ & $(95 \%$ Cl) & OR & $(95 \% \mathrm{Cl})$ & $O R$ & $(95 \% \mathrm{Cl})$ & OR & $(95 \% \mathrm{Cl})$ & $O R$ & $(95 \%$ Cl) & \\
\hline $\begin{array}{l}\text { Hypertension: "Low risk" }{ }^{4} \text { at baseline } \\
\text { to "High risk"* at follow-up }\end{array}$ & 241 & 1.09 & $(0.83,1.41)$ & 1.08 & $(0.84,1.38)$ & 0.93 & $(0.70,1.22)$ & 0.97 & $(0.76,1.24)$ & 0.94 & $(0.70-1.24)$ & 1.10 & $(0.85-1.43)$ & 1.00 \\
\hline $\begin{array}{l}\text { Total cholesterol: " Low risk" }{ }^{4} \text { at } \\
\text { baseline to "High risk"* at follow-up }\end{array}$ & 162 & 0.97 & $(0.61,1.55)$ & 0.81 & $(0.52,1.25)$ & 0.94 & $(0.58,1.52)$ & 0.79 & $(0.51,1.23)$ & 1.01 & $(0.61-1.68)$ & 0.77 & $(0.49-1.22)$ & 1.00 \\
\hline $\begin{array}{l}\text { Body mass index: "Low risk" }{ }^{\mathbf{4}} \text { at } \\
\text { baseline to "High risk"^ at follow-up }\end{array}$ & 177 & 0.93 & $(0.60,1.46)$ & 1.14 & $(0.75,1.71)$ & 1.02 & $(0.64,1.63)$ & 1.21 & $(0.80,1.84)$ & 0.88 & $(0.45-1.6)$ & 1.08 & $(0.65-1.78)$ & 1.00 \\
\hline \multirow[t]{4}{*}{$\begin{array}{l}\text { No diabetes at baseline to diabetes at } \\
\text { follow-up }\end{array}$} & 90 & 2.05 & $(1.32,3.18)$ & 0.88 & $(0.47,1.65)$ & 1.71 & $(1.10,2.66)$ & 0.78 & $(0.41,1.48)$ & 1.55 & $(0.97-2.49)$ & 0.69 & $(0.36-1.29)$ & 1.00 \\
\hline & \multicolumn{14}{|c|}{ Women } \\
\hline & & \multicolumn{2}{|c|}{ Secondary } & \multicolumn{2}{|c|}{ Diploma } & \multicolumn{2}{|c|}{ Secondary } & \multicolumn{2}{|c|}{ Diploma } & \multicolumn{2}{|c|}{ Secondary } & \multicolumn{2}{|c|}{ Diploma } & Degree \\
\hline & $n$ & OR & $(95 \%$ Cl) & OR & $(95 \%$ Cl) & OR & $(95 \%$ Cl) & OR & $(95 \%$ Cl) & OR & $(95 \%$ Cl) & $O R$ & $(95 \%$ Cl) & $\begin{array}{l}\text { (reference } \\
\text { category for } \\
\text { all models) }\end{array}$ \\
\hline $\begin{array}{l}\text { Hypertension: "Low risk" at baseline } \\
\text { to "High risk"* at follow-up }\end{array}$ & 275 & 1.68 & $(1.10,2.56)$ & 1.41 & $(0.90,2.19)$ & 1.14 & $(0.73,1.77)$ & 1.09 & $(0.71,1.68)$ & 1.00 & $(0.63-1.59)$ & 0.99 & $(0.62-1.60)$ & 1.00 \\
\hline $\begin{array}{l}\text { Total cholesterol. " Low risk" }{ }^{4} \text { at } \\
\text { baseline to "High risk"* at follow-up }\end{array}$ & 260 & 1.44 & $(0.95,2.19)$ & 1.34 & (0.85 2.12) & 1.20 & $(0.76,1.90)$ & 1.27 & $(0.80,2.02)$ & 1.10 & $(0.68-1.76)$ & 1.20 & $(0.76-1.89)$ & 1.00 \\
\hline $\begin{array}{l}\text { Body mass index. "Low risk" at } \\
\text { baseline to "High risk"* at follow-up }\end{array}$ & 311 & 1.51 & $(1.01,2.27)$ & 1.69 & $(1.23,2.33)$ & 1.54 & $(1.04,2.27)$ & 1.70 & $(1.24,2.34)$ & 1.34 & $(0.82-2.17)$ & 1.48 & $(0.98-2.24)$ & 1.00 \\
\hline $\begin{array}{l}\text { No diabetes at baseline to diabetes at } \\
\text { follow-up }\end{array}$ & 86 & 3.20 & $(1.36,7.50)$ & 2.68 & $(1.14,6.31)$ & 3.09 & $(1.28,7.42)$ & 2.65 & $(1.11,6.30)$ & 2.69 & $(1.04-6.98)$ & 2.52 & $(1.01-6.30)$ & 1.00 \\
\hline
\end{tabular}

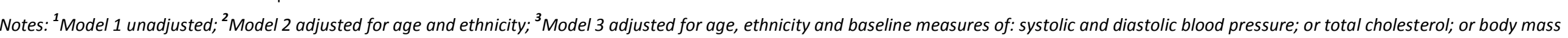

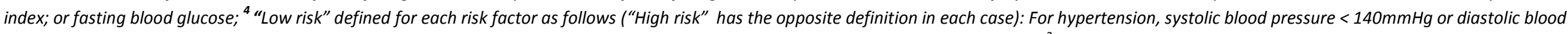
pressure $<90 \mathrm{mmHg}$ and not on blood pressure lowering medication; for cholesterol $<5.5 \mathrm{mmol} / \mathrm{l}$ and not on treatment; for BMI $<25 \mathrm{~kg} / \mathrm{m}^{2} ;$ for diabetes, no known or newly diagnosed diabetes:

Abbreviations $\mathrm{OR}=$ Odds ratio; $\mathrm{Cl}=$ confidence interval.

Model $3^{3}$

Model $2^{2}$

\section{Men}


Table 4. Difference in the number of risk factors ${ }^{1}$ between baseline and 5 year follow up in male and female AusDiab participants according to educational attainment

Model 1 - adjusted for baseline risk factor number ${ }^{2}$

Secondary

Diploma

Degree

$p$ for
trend $^{3}$

coefficient $\quad(95 \% \mathrm{Cl}) \quad$ coefficient $\quad(95 \% \mathrm{Cl}) \quad$ ref

Increase in mean number of risk factors

between baseline and follow up
0.09

$(-0.01,0.19)$

0.02

$(-0.05,0.09)$

$0.14 \quad(0.06,0.21)$

0.11

$(0.04,0.18)$ ref

0.006
Model 2 - adjusted for baseline risk factor number, age \& ethnicity

Notes: ${ }^{1}$ Presence of each risk factor defined as follows: For hypertension, systolic blood pressure $<140 \mathrm{mmHg}$ or diastolic blood pressure $<90 \mathrm{mmHg}$ and not on blood pressure

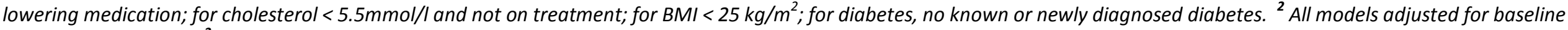
number of risk factors. ${ }^{3} \mathrm{p}$ for trend across educational categories using linear regression: Abbreviations $\mathrm{Cl}=$ confidence interval. 


\section{Change in smoking status}

The proportions of current smokers decreased between baseline and follow up in most educational groups (data not shown). Participants with lower education were more likely to stop smoking between baseline and follow up, than those with higher education. Among men, age and ethnicity-adjusted odds ratios for smoking cessation for secondary compared to tertiary education were $2.55(95 \% \mathrm{Cl} 1.31-4.94)$, and for diploma compared to tertiary education, $1.78(95 \% \mathrm{Cl} 1.01-3.15)$. For women, the corresponding odds ratios were 3.74 $(95 \% \mathrm{Cl} 1.42-9.86)$ and $2.54(95 \% \mathrm{Cl} 0.95-6.82)$, respectively.

\section{Increase in the number of risk factors}

After adjusting for age and ethnicity, and for the number of risk factors at baseline, women with lower education had an increased mean number of risk factors at follow up compared to women with higher education (increased by $0.10,(95 \% \mathrm{Cl} 0.02$ $0.19)$ for secondary education and $0.09,(95 \% \mathrm{Cl}$ 0.02-0.17) for diploma education in comparison to degree-level education). No relationship was observed for males.

\section{Discussion}

\section{Overall findings}

This study found that over 5 years, lower education was positively associated with the onset of overweight/ obesity in women, and of diabetes in both men and women. The likelihood of accumulating a higher number of risk factors between baseline and follow up was greater for lower compared to higher educated women.

\section{Strengths and limitations}

This contemporary study was undertaken on a large sample with accurate measurement of risk factors. However, there was a significant loss to follow-up, and so the sample may not be representative of the Australian population, limiting the generalisability of the results from this study. Non-attendance was associated with lower educational attainment in both men and women and this may lead to some selection bias and possible underestimation of our findings. In addition, the prevalence of smoking was higher among non-attendees. However, this was the case for all educational groups and therefore would be unlikely to affect our findings concerning the relationship between education and smoking. We described risk using categories rather than continuous measurements. There is known to be a continuous relationship between risk factor levels and risk of disease; as a risk factor progressively increases, so too does the risk of developing CVD (Law 2002). While our results therefore do not present information regarding risk accumulation across the entire risk spectrum, describing development of high risk in this manner may be more meaningful and applicable to clinicians. For example, clinical guidelines for the prevention of atherosclerotic heart disease use risk factor cut-off points as indicators of treatment (National Heart Foundation 2007; Pearson et al 2002: European Society of Cardiology 2007).

While we used one indicator only to measure SEP, education is considered a robust measure as it is relatively easy to measure, has high response rates, tends to exclude fewer members of the population than occupational-based measures, and is less likely to change after adulthood than other indicators (Shavers 2007, Dutton et al 2005). Many studies have demonstrated consistent associations between education level and CVD risk factors, both singly and accumulated (Helmert et al 1990; Winkleby et al 1992; Luoto et al 1994; Choiniere et al 2000; Yu et al 2000; Stelmach et al 2004; Maty et al 2005; Robbins et al 2005). Educational attainment has also been shown to have a strong association with CVD mortality (Winkleby et al 1992; Kilander et al 2001; Lee et al 2005). There are several mechanisms through which education might influence health status. For example, education provides knowledge and life skills that allow people to gain ready access to information and health promotion resources (Adler and Newman 2002). Individuals with higher education may also be more likely to have better work and economic conditions and psychological resources, although the stability of education can sometimes mask changes in an individual's circumstances. It is important to note however, that no single indicator will capture all aspects of SEP.

The meaning of educational attainment will also vary between different birth cohorts as school leaving age increases, or higher education becomes more widely available. For example, in Australia in 1945, the majority of school children completed only 2-3 years of secondary education, whereas in 1971, more than half completed 4 years. In 1939, 
less than 3 percent of adults aged 17-22 were in full-time tertiary education; in 1971 this was 9 percent (Encel 1972). It is difficult to assess the effect of this upon our results. Our analysis controlled for age, which may have mediated some of the effects of changes in education policy, nevertheless this may prove to be an important limitation on the use of educational attainment as a measurement of SEP in longitudinal studies that contain multiple birth cohorts.

\section{Individual risk factors}

Consistent with our findings, several longitudinal studies report that lower SEP is associated with incident overweight or obesity over time (Ball et al 2002; Coogan et al 2010). We also found that lower educated women of normal weight were more likely to progress to incident overweight or obesity than were those with higher education. This may be driven by the higher mean BMI observed at baseline among women with lower education, as the association was no longer significant after adjustment for baseline BMI. There was no educational gradient seen in BMI among men of normal weight, possibly accounting for some of the differences seen in our study between men and women. Gender-related differences in the social gradient in BMI gain have also been reported by others, although findings are conflicting (Matheson et al 2008; Ross et al 2007; Dennis et al 2000; Sundquist and Johansson 1998). Overweight or obesity has previously been associated with other risk factors such as diabetes and systolic blood pressure (Dennis et al 2000). Therefore, the contribution of BMI to future socioeconomic gradients in CVD is potentially of great importance, particularly among women.

Other studies also report that diabetes incidence is inversely associated with SEP (Kumari et al 2004; Maty et al 2005; Maty et al 2010; Krishnan et al 2010; Lidfeldt et al 2007). The greater incidence of diabetes among lower educated women in our study may be related to the co-existing increases seen in overweight and obesity. Several studies report an attenuation of the effect of SEP on incident diabetes after adjusting for BMI (Maty et al 2005; Robbins et al 2005; Krishnan et al 2010; Lidfeldt et al 2007), suggesting that obesity is an important mediator in this relationship. However, in our study, the social gradient in diabetes is much stronger than that seen for BMI, implying that other factors may play a part.
There was no educational gradient seen in incident hypertension in either men or women. Few studies have examined incident hypertension according to SEP, with most finding that education, income and neighbourhood are all predictors of onset of this risk factor (Diez Roux et al 2002; Dyer et al 1999; Vargas et al 2000; Conen et al 2000). The lack of a significant finding in our study may reflect small numbers of incident hypertension. While there was no educational gradient seen in mean systolic blood pressure among men who were "not at risk" for hypertension at baseline (Table 2), a gradient was apparent when the total population was examined (including those on anti-hypertensive medication). This may indicate educational differences in the treatment of hypertension among men.

We found the prevalence of smoking declined across all socio-economic groups, apart from among women with degree level education. Similar to other studies, the pattern was one of a greater decrease among the lower educated (Kanjilal et al 2006; Lyratzopolous et al 2006; Strand and Tverdal 2006). These findings are likely to reflect secular trends in smoking due to the effect of public health policies such as increased tobacco taxation. This strategy is considered one of the most effective deterrents to smoking, and has been shown to be effective among lower SEP groups in some settings including Australia (White et al 2003). Overall our findings are encouraging, as smoking has previously been shown to contribute to approximately $30 \%$ of the excess risk of CVD mortality among lower SEP groups (Jha et al 2006).

\section{Multiple risk factors}

It is known that having more than one risk factor can accelerate the development of atherosclerosis and CVD mortality (Lowe et al 1998; Berenson et al 1998), and that socio-economic disadvantage is inversely associated with the number of risk factors present (AlHW 2005). The pattern of a smaller number of risk factors in higher SEP groups and a greater number in lower SEP groups seen in our study has been observed by others (AlHW 2005; Karlamangla et al 2005), however, few studies have examined the accumulation of risk factors over time according to SEP (Dupre 2008; Karlamangla et al 2005). One United States study, utilising 20 years of data from the National Health and Nutrition Epidemiologic Follow-up Study, reported that education was 
associated with the accumulation of behavioural risk factors for CVD, namely smoking, alcohol and obesity (Dupre 2008). Our results also showed that women with lower education were more likely than those with higher education to increase their number of risk factors over time, potentially contributing to continued socio-economic gradients in CVD in the future.

\section{Implications}

Our findings have important implications for the future burden of CVD among lower educated groups. They suggest that people with less education carry a greater burden of individual cardiovascular risk factors, and are also more likely to progress to an overall increased risk. Our findings also suggest that more educated participants, particularly females, are less likely to develop incident risk factors, which together with the existing social gradient, will potentially lead to increased gradients over time. These findings thus reinforce the need to direct intervention efforts towards reducing socio-economic differences in CVD.

Not only do our results have implications for the development of CVD, but for other risk factors and conditions more broadly. Obesity has been associated with a wide range of chronic conditions such as diabetes, hypertension, kidney disease, and certain cancers (Field et al 2001; Kramer et al 2005; Wang et al 2008). Being obese also influences the ability to successfully manage many chronic conditions such as arthritis (Ogden et al 2007; AlHW 2005). It is therefore possible that educational gradients in the incidence of these risk factors will adversely impact upon educational gradients in chronic diseases overall.
The implications of the gender-based differences seen in our study are also of interest. The adverse effects of cardiovascular risk factors have previously been shown to be stronger for women compared to men (Chrysohoou et al 2003; $\mathrm{Yu}$ et al 2000). For example in the INTERHEART study, the population attributable risk for hypertension was $36 \%$ in women and $19 \%$ in men (Yusuf et al 2004). Diabetes has also been associated with a higher risk of CHD in women than in men (Haffner et al 1997), although this may be due to the fact that women also tend to have a higher number of coexisting risk factors than men (Kanaya et al 2002; Oda et al 2006). The reasons for these gender-based differences in CVD risk are unclear although patho-physiological factors, or treatment differences, may play a role (Vaccarino 2010). In addition, CVD risk factors have been more consistently and strongly associated with SEP among women compared to men (Strand and Tverdal 2006; Lyrotzopolous et al 2006; Luepker et al 1993; Bennett 1995; Yu et al 2000; Helmert et al 1990). Findings such as ours, that show an increased incidence of major risk factors among women, suggest that social gradients in CVD events will continue to widen among women.

\section{Conclusion}

Our findings provide evidence for the association between SEP and incident cardiovascular risk factors for CVD in a cohort of Australian men and women. Among women in particular, lower education was associated with an increased risk of developing both individual and accumulated CVD risk factors over a 5-year period. These findings suggest that educational inequalities in CVD will continue into the future.

\section{Acknowledgements}

The AusDiab study, co-coordinated by the Baker IDI Heart and Diabetes Institute, gratefully acknowledges the generous support given by:

National Health and Medical Research Council (NHMRC grant 233200), Australian Government Department of Health and Ageing. Abbott Australasia Pty Ltd, Alphapharm Pty Ltd, AstraZeneca, Bristol-Myers Squibb, City Health Centre-Diabetes Service-Canberra, Department of Health and Community Services - Northern Territory, Department of Health and Human Services - Tasmania, Department of Health - New South Wales, Department of Health - Western Australia, Department of Health - South Australia, Department of Human Services - Victoria, Diabetes Australia, Diabetes Australia Northern Territory, Eli Lilly Australia, Estate of the Late Edward Wilson, GlaxoSmithKline, Jack Brockhoff Foundation, Janssen-Cilag,, Kidney Health Australia, Marian \& FH Flack Trust, Menzies Research Institute, Merck Sharp \& Dohme, Novartis Pharmaceuticals, Novo Nordisk Pharmaceuticals, Pfizer Pty Ltd, Pratt Foundation, Queensland Health, Roche Diagnostics 
Australia, Royal Prince Alfred Hospital, Sydney, Sanofi Aventis, Sanofi Synthelabo. Also, for their invaluable contribution to the set-up and field activities of AusDiab, we are enormously grateful to A Allman, B Atkins, S Bennett, A Bonney, S Chadban, $M$ de Courten, $M$ Dalton, D Dunstan, T Dwyer, $H$ Jahangir, D Jolley, D McCarty, A Meehan, N Meinig, S Murray, K O'Dea, K Polkinghorne, P Phillips, C Reid, A Stewart, R Tapp, H Taylor, T Whalen, F Wilson and Paul Zimmet.

\section{Funding}

This work was supported by the National Health and Medical Research Council (NHMRC) (ID No. 465352 for AB, ID No. 390109 for GT, ID No. 586623 for JS). AP is funded by a VicHealth Fellowship.

\section{References}

Australian Institute of Health and Welfare: O'Brien K. (2005) Living dangerously: Australians with multiple risk factors for cardiovascular disease. Bulletin No. 24, AIHW Cat. No. AUS 57, Canberra: AlHW. http://www.aihw.gov.au/publications/aus/bulletin24/bulletin24.pdf

Australian Institute of Health and Welfare: Moon L and A Waters. (2006) Socioeconomic inequalities in cardiovascular disease in Australia: current picture and trends since the 1990s. Bulletin No. 37. AlHW cat. no. AUS 74. Canberra: AlHW.

http://www.aihw.gov.au/publications/aus/bulletin37/bulletin37.pdf

Ball K, Crawford D, Ireland P and Hodge A. (2002) Patterns and demographic predictors of 5-year weight change in a multi-ethnic cohort of men and women in Australia. Public Health Nutrition, 6, 269-280. http://journals.cambridge.org/action/displayFulltext?type=1\&fid=628380\&jid=PHN\&volumeld=6\&iss ueld $=03 \&$ aid $=567488$

Ball K and Crawford D. (2005) Socio-economic status and weight change in adults: a review. Social Science and Medicine, 60, 1987-2010. http://linkinghub.elsevier.com/retrieve/pii/S0277953604004678

Beauchamp A, Peeters A, Wolfe R, Turrell G, Harriss L, Giles G, English D, McNeil J, Magliano D, Harrap S, Liew D, Hunt D and Tonkin A. (2010) Inequalities in cardiovascular disease mortality: the role of behavioural, physiological and social risk factors. Journal of Epidemiology and Community Health, 64,542-548.

http://jech.bmj.com/content/64/6/542.abstract

Berenson G, Srinivasan S, Bao W, Newman W, Tracey R and Wattigney W. (1998) Association between multiple cardiovascular risk factors and atherosclerosis in children and young adults. New England Journal of Medicine, 338, 1650-6. http://www.nejm.org/doi/pdf/10.1056/NEJM199806043382302

Briganti E, J Shaw, S Chadban, P Zimmet, T Welborn, J McNeil and Atkins R. (2003) Untreated hypertension among Australian adults: the 1999-2000 Australian Diabetes, Obesity and Lifestyle study (AusDiab) Medical Journal of Australia, 179, 135-139. http://www.mia.com.au/public/issues/179 03 040803/bri10876 fm.pdf

Choiniere RP, Lafontaine P and Edwards A. (2000) Distribution of cardiovascular disease risk factors by socioeconomic status among Canadian adults. Canadian Medical Association Journal 162(9 Suppl), S13-24. http://www.ncbi.nlm.nih.gov/pubmed/10813023

Conen D, Glynn R, Ridker P, Buring J and Albert M. (2009) Socio-economic status, blood pressure progression and incident hypertension in a prospective cohort of female health professionals. European Heart Journal, 30, 1378-1384. http://eurheartj.oxfordjournals.org/content/30/11/1378

Coogan P, Cozier Y, Krishnan S, Wise L, Adams-Campbell L, Rosenberg L and J Palmer. (2010) Neighborhood socioeconomic status in relation to 10-year weight gain in the Black Women's Health Study. Obesity, 18, 2064-2065. http://www.nature.com/oby/journal/v18/n10/abs/oby201069a.html

Dalton M, Cameron J, Zimmet P, Shaw J, Jolley D, Dunstan D and Welborn T. (2003) Waist circumference, waist-hip ratio and body mass index and their correlation with cardiovascular disease risk factors in Australian Adults. Journal of Internal Medicine, 254, 555-563. http://onlinelibrary.wiley.com/doi/10.1111/i.1365-2796.2003.01229.x/full

Dennis, B., Pajak A, Pardo B, Davis C, Williams O and Piotrowski W. (2000) Weight gain and its correlates in Poland between 1983 and 1993. International Journal of Obesity and Related Metabolic Disorders, 24, 1507-13. http://cat.inist.fr/?aModele=afficheN\&cpsidt=820499

Diez Roux A, Chambless L, Stein Merkin S, Arnett D, Eigenbrodt M, Nieto J, Szklo M and Sorlie P. (2002) Socio-economic disadvantage and change in blood pressure associated with ageing. Circulation, 106, 703-710. 
http://circ.ahajournals.org/cgi/content/short/106/6/703

Dupre M. (2008) Educational differences in health risks and illness over the lifecourse: a test of cumulative disadvantage. Social Science Research, 37, 1253-1266.

http://www.sciencedirect.com/science? ob=ArticleURL\& udi=B6WX8-4SW859B-

$1 \&$ user $=10 \&$ coverDate $=12 \% 2 F 31 \% 2 F 2008 \&$ rdoc $=1 \&$ fmt=high \& orig=search \& origin=search \& sort $=d \&$ docanchor $=\& v i e w=c \&$ searchStrld $=1587127099 \&$ rerunOrigin $=$ google \& acct $=C 000050221$ \& version=1\& urlVersion=0\& userid=10\&md5=8fc9cc4fedbbe68edd246b10c0910bd2\&searchtype $=$ $\underline{\mathrm{a}}$

Dunstan D, Zimmet P, Welborn T, Cameron A, Shaw J, De Courten M, Jolley D, McCarty D and the AusDiab Steering Committee. (2002) The Australian Diabetes, Obesity and Lifestyle study (AusDiab) methods and response rates. Diabetes Research and Clinical Practice, 57, 119-129. http://www.diabetesresearchclinicalpractice.com/article/S0168-8227(02)00025-6/abstract

Dutton T, Turrell G and Oldenburg B. (2005) Measuring socioeconomic position in population health monitoring and health research, Health Inequalities Monitoring Series No. 2, Queensland University of Technology, Brisbane.

Dyer A, Liu K, Walsh M, Kiefe C, Jacobs D and Bild D. (1999) Ten-year incidence of elevated blood pressure and its predictors: the CARDIA study. Journal of Human Hypertension, 13, 13-21. http://www.nature.com/jhh/journal/v13/n1/abs/1000740a.html

European Society of Cardiology and Other Societies on Cardiovascular Disease Prevention in Clinical Practice. (2007) European guidelines on cardiovascular disease prevention in clinical practice: executive summary. European Journal of Cardiovascular Prevention \& Rehabilitation 14(Supp 2): E1-E40. http://eurheartj.oxfordjournals.org/content/28/19/2375.full

Ford $\mathrm{E}$ and Cooper R. (1991) Risk factors for hypertension in a national cohort study. Hypertension, 18, 598606.

http://hyper.ahajournals.org/cgi/content/short/18/5/598

Helmert U, Shea $\mathrm{H}$ and Greiser E. (1990) Relationship of social class characteristics and risk factors for coronary heart disease in West Germany. Public Health 104, 399-416. http://www.ncbi.nlm.nih.gov/pubmed/2274644

Jha P, Chaloupka F, Corrao M and Jacob B. (2006) Reducing the burden of smoking world-wide: effectiveness of interventions and their coverage. Drug and Alcohol Review, 25, 597-609. http://onlinelibrary.wiley.com/doi/10.1080/09595230600944511/abstract

Kanjilal S, Gregg E, Cheng Y, Zhang P, Nelson D, Mensah G and Beckles G. (2006) Socio-economic status and trends in disparities in 4 major risk factors for cardiovascular disease among US adults, 1971-2002. Archives Internal Medicine, 166, 2348-2355. http://www.ncbi.nlm.nih.gov/pubmed/17130388

Kaplan $\mathrm{G}$ and Keill J. (1993) Socio-economic factors and cardiovascular disease: a review of the literature. Circulation, 88, 1973-1998. http://circ.ahajournals.org/cgi/content/short/88/4/1973

Karlamangla A, Singer B, Williams D, Schwartz J, Matthews K, Kiefe C and Seeman T. (2005) Impact of socioeconomic status on longitudinal accumulation of cardiovascular risk in young adults: the CARDIA Study (USA). Social Science \& Medicine, 60, 999-1015.

http://www.sciencedirect.com/science? ob=ArticleURL\& udi=B6VBF-4D98GNM$2 \&$ user $=7343059 \&$ coverDate $=03 \% 2 \mathrm{~F} 01 \% 2 \mathrm{~F} 2005 \&$ rdoc $=1 \& \mathrm{fmt}=$ high \& orig $=$ search \& origin=sea rch\& sort $=d \&$ docanchor $=\&$ view $=c \&$ searchStrld $=1596640119 \&$ rerunOrigin $=$ google \& acct $=$ C0000 71786\& version $=1 \&$ urlVersion $=0$ \& userid $=7343059 \& \mathrm{md} 5=433 \mathrm{c} 1 \mathrm{fe} 2 \mathrm{ba} 81 \mathrm{a0fb} 4 \mathrm{a} 44 \mathrm{de} 35 \mathrm{c} 8 \mathrm{~b} 20 \mathrm{dd} 2$ \&searchtype $=\mathrm{a}$

Khan F, Zia E, Janzon L, and Engstrom G. (2004) Incidence of stroke and stroke subtypes in Malmö, Sweden, 1990-2000: marked differences between groups defined by birth country. Stroke, 35, 2054-8. http://stroke.ahajournals.org/cgi/content/abstract/01.STR.0000135761.18954.0bv1

Kilander L, Berglund L, Boberg M, Vessby B and Lithell H. (2001) Education, lifestyle factors and mortality from cardiovascular disease and cancer. A 25-year follow-up of Swedish 50-year-old men. International Journal of Epidemiology, 30, 1119-1126. http://ije.oxfordjournals.org/content/30/5/1119.abstract

Krishnan S, Cozier Y, Rosenberg L and Palmer J. (2010) Socio-economic status and incidence of type 2 diabetes: results from the Black Women's Health Study. American Journal of Epidemiology, 171, 564570. http://aje.oxfordjournals.org/content/171/5/564.full

Kumari M, Head J and Marmot M. (2004) Prospective study of social and other risk factors for incidence of type II diabetes in the Whitehall II study Archives of Internal Medicine, 164, 1873-1880. http://archinte.ama-assn.org/cgi/reprint/164/17/1873.pdf

Law $M$ and Wald N. (2002) Risk factor thresholds: their existence under scrutiny. British Medical Journal, 324, 1570-6.

http://www.bmj.com/content/324/7353/1570.extract 
Lee J, Paultre F and Mosca L. (2005) The association between educational level and risk of cardiovascular disease fatality among women with cardiovascular disease. Women's Health Issues, 15, 80-88. http://www.sciencedirect.com/science/article/pii/S1049386704001185

Lidfeldt J, Li T, Hu F, Manson J and Kawachi I. (2007) A prospective study of childhood and adult socioeconomic status and incidence of type 2 diabetes in women. American Journal of Epidemiology, $168,882-889$.

http://aje.oxfordjournals.org/content/165/8/882.abstract

Lowe L, Greenland P, Ruth K, Dyer A, Stamler R and Stamler J. (1998) Impact of major cardiovascular disease risk factors, particularly in combination, on 22-year mortality in women and men. Archives of Internal Medicine, 158, 2007-14. http://archinte.ama-assn.org/cgi/content/abstract/158/18/2007

Luoto R, Pekkanen $U$ and Tuomilehto J. (1994) Cardiovascular risks and socio-economic status: differences between men and women in Finland. Journal of Epidemiology and Community Health, 48, 348-354. http://www.jstor.org/stable/25567935

Lynch J, Kaplan G, Cohen R, Tuomilehto J and Salonen J. (1996) Do cardiovascular risk factors explain the relation between socioeconomic status, risk of all-cause mortality, cardiovascular mortality, and acute myocardial infarction? American Journal of Epidemiology, 144, 934-942. http://aje.oxfordjournals.org/content/144/10/934.full.pdf

Lynch J, Davey Smith G, Harper S and Bainbridge K. (2006) Explaining the social gradient in coronary heart disease: comparing relative and absolute risk approaches. Journal of Epidemiology and Community Health, 60, 436-441. http://jech.bmj.com/content/60/5/436

Lyratzopoulos G, Heller R, McElduff P, Hanily M and Lewis P. (2006) Deprivation and trends in blood pressure, cholesterol, body mass index and smoking among participants of a UK primary care-based cardiovascular risk factor screening programme: both narrowing and widening in cardiovascular risk factor inequalities. Heart, 92, 1198-1206. http://heart.bmj.com/content/92/9/1198.abstract

Mackenbach J, Stirbu I, Roskam A, Schaap M, Menvielle G, Leinsalu M and Kunst A. (2008) Socio-economic inequalities in health in 22 European countries. New England Journal of Medicine, 358, 2468-2481. http://www.nejm.org/doi/full/10.1056/NEJMsa0707519

Magliano D, Barr E, Zimmett P, Cameron J, Dunstan D, Colagiuri S, Jolley D, Owen N, Phillips P, Tapp R, Welborn T and Shaw J. (2007) Glucose indices, health behaviours and incidence of diabetes in Australia: the AusDiab study Diabetes Care, 31, 267-272. http://care.diabetesjournals.org/content/31/2/267.abstract

Marmot M, Friel S, Bell R, Houweling T and Taylor S. (2008) Closing the gap in a generation: health equity through action on the social determinants of health. The Lancet 372,1661-1669. http://www.who.int/social determinants/thecommission/finalreport/en/index.html

Marmot M. (1992) Coronary heart disease: rise and fall of an epidemic. In M Marmot and P Elliott. Coronary heart disease epidemiology. Oxford University Press, Oxford.

Marmot M. (2010) Fair society, healthy lives, the Marmot review. http://www.ucl.ac.uk/marmotreview.

Martikeinen P and Marmot M. (1999) Socio-economic differences in weight gain and determinants and consequences of coronary risk factors. American Journal of Clinical Nutrition, 64, 719-726. http://www.ajcn.org/content/69/4/719.abstract

Matheson F, Moineddin R and Glazier R. (2008) The weight of place: a multilevel analysis of gender, neighbourhood material deprivation, and body mass index among Canadian adults. Social Science and Medicine, 66, 675-90. http://www.ncbi.nlm.nih.gov/pubmed/18036712

Matthews K, Kiefe C, Lewis C, Liu K, Sidney S and Yunis C. (2002) Socioeconomic trajectories and incident hypertension in a biracial cohort of young adults. Hypertension, 39, 772-776. http://hyper.ahajournals.org/cgi/content/short/39/3/772

Maty S, Everson-Rose S, Haan M, Raghunathan T and Kaplan G. (2005) Education, income, occupation and the 34-year incidence (1965-99) of type 2 diabetes in the Alameda County study International Journal of Epidemiology, 34, 1274-1281. http://ije.oxfordjournals.org/content/34/6/1274.abstract

Maty S, James S and Kaplan G. (2010) Life-course socio-economic position and incidence of diabetes mellitus among blacks and whites: the Alameda County study. American Journal of Public Health, 100, 137145. http://ajph.aphapublications.org/cgi/content/short/100/1/137

McLaren L. (2007) Socioeconomic status and obesity. Epidemiologic Reviews, 29, 29-48. http://epirev.oxfordjournals.org/content/29/1/29.full 
Mujahid M, Diez Roux A, Borrell L and Nieto F. (2005) Cross-sectional and longitudinal associations of BMI with socioeconomic characteristics. Obesity Research, 13, 1412-1421. http://www.nature.com/oby/journal/v13/n8/full/oby2005171a.html

National Heart Foundation and Cardiac Society of Australia and New Zealand. (2007) Reducing Risk in Heart Disease.

http://www.heartfoundation.org.au/SiteCollectionDocuments/Reduce-risk-in-heart-diseaseguideline.pdf

National Vascular Disease Prevention Alliance. (2009) Guidelines for the assessment of absolute cardiovascular disease risk. http://www.heartfoundation.org.au/SiteCollectionDocuments/A AR QRG FINAL\%20FOR\%20WEB.p df

Pearson T, Blair S, Daniels S, Eckel R, Fair J, Fortmann S, Franklin B, Goldstein L, Greenland P, Grundy S, Hong Y, Houston Miller N, Lauer R, Ockene I, Sacco R, Sallis J, Smith S, Stone N and Taubert K. (2002) Guidelines for Primary Prevention of Cardiovascular Disease and Stroke: 2002 Update. Circulation, 106: 388-391.

http://circ.ahajournals.org/cgi/content/full/106/3/388

Robbins J, Vaccarino V, Zheng H and Kasl S. (2005) Socio-economic status and diagnosed diabetes incidence. Diabetes Research and Clinical Practice, 68, 230-236.

http://www.diabetesresearchclinicalpractice.com/article/S0168-8227(04)00301-8/abstract

Ross N, Tremblay S, Khan S, Crouse D, Tremblay M and Berthelot J. (2007) Body mass index in urban Canada: neighbourhood and metropolitan area effects. American Journal of Public Health, 97, 500-8. http://ajph.aphapublications.org/cgi/content/short/97/3/500

Shavers V. (2007) Measurement of socio-economic status in health disparities research. Journal of the National Medical Association, 99, 1013-1023. http://www.ncbi.nlm.nih.gov/pmc/articles/PMC2575866/?tool=pubmed

Smith J. (2007) Nature and causes of trends in male diabetes prevalence, undiagnosed diabetes, and the socio-economic status health gradient. Proceedings of the National Academy of Sciences, 104, 13225-13231. http://www.pnas.org/content/104/33/13225.abstract

Stelmach W, Kaczmarczyk-Chalas K, Bielecki W, Stelmach I and Drygas W. (2004) How income and education contribute to risk factors for cardiovascular disease in the elderly in a former communist country. Public Health, 118, 439-449. http://www.ncbi.nlm.nih.gov/pubmed/15313598

Strand B and Tverdal A. (2006) Trends in educational inequalities in cardiovascular risk factors: A longitudinal study among 48,000 middle-aged Norwegian men and women. European Journal of Epidemiology, 21, 731-739. http://www.springerlink.com/content/x5tw06n38r8050v0/

Sundquist J and Johansson S. (1998) The influence of socioeconomic status, ethnicity and lifestyle on body mass index in a longitudinal study. International Journal of Epidemiology, 27, 57-63. http://ije.oxfordjournals.org/content/27/1/57.abstract

Vargas C, Ingram D and Gillum R. (2000) Incidence of hypertension and educational attainment. American Journal of Epidemiology, 152, 272-278. http://aje.oxfordjournals.org/content/152/3/272.full

White V, Hill D, Siahpush M and Bobevski I. (2003) How has the prevalence of cigarette smoking changed among Australian adults? Trends in smoking prevalence between 1980 and 2001. Tobacco Control, $12,67 i i-74$. http://tobaccocontrol.bmj.com/content/12/suppl 2/ii67.abstract

Winkleby M, Jatulis F and Fortmann S. (1992) Socio-economic status and health: How education, income, and occupation contribute to risk factors for cardiovascular disease. American Journal of Public Health, 82, 816-820. http://www.ncbi.nlm.nih.gov/pmc/articles/PMC1694190/

Yu Z, Nissinen A, Vartiainen E, Song G, Guo Z, Zheng G, Tuomilehto J and Tian H. (2000) Associations between socio-economic status and cardiovascular risk factors in an urban population in China. Bulletin of the World Health Organization, 78, 1296-1305. http://www.ncbi.nlm.nih.gov/pubmed/11143189

Yusuf S, Hawken S, Ônpuu S, Dans T, Avezum A, Lanas F, McQueen M, Budaj A, Pais P, Varigos J and Lisheng L. (2004) Effects of potentially modifiable risk factors associated with myocardial infarction in 52 countries (the INTERHEART study). Lancet, 364, 937 - 952. http://www.thelancet.com/journals/lancet/article/PIIS0140-6736(04)17018-9/abstract 